\title{
SPECTROSCOPIC EVIDENCE FOR A CONTINUOUS CHANGE IN MOLECULAR AND CRYSTAL STRUCTURE: DEFORMATION OF BIPHENYL IN THE LOW TEMPERATURE SOLID ${ }^{\text {it }}$
}

\author{
Peter S. FRIEDMAN, Rzoul KOPELMAN and Paras N. PRASAD \\ Deparment of Chemistry, The University of Michigan. Am Arbor, Michigan 48IO4, USA
}

Received 30 September 1973

\begin{abstract}
A Raman temperature study of biphenyl- $h_{10}$ and biphenyl-d ${ }_{10}$ crystuls reveals an unusual spectral chunge over a wide temperature region. Many internal and external infrared-ictive modes appear gradually as the temperature is lowered from about 75 to $15^{\circ} \mathrm{K}$. We interpret this as a mild and gradual change in both crystal and inolecular structure: a loss of center of inversion, probably involving the parfial refurn ol the molecule to its non-planar slape $\left(\mathrm{D}_{2}\right)$ in the vapor phase.
\end{abstract}

We report here what appears to be a non-monotonic behavior of the molecular structure of biplienyl in its condensed phases. Biphenyl has been reported to be non-planar in the gas phase $[1-3]$, in solution $[2,3]$ and in the melt [2]. However, X-ray crystallography [4] (room temperature) shows the molecule to be planar $\left(D_{2 h}\right)$ and the crystal centrosymmetric $\left(C_{2 h}^{5}\right)$. We present below spectroscopic evidence for a contimuous structural change occurring in the crystal at low temperature, characterized by the molecule becoming noncentrosymmetric and implying the existence of a corresponding continuous phase transition.

In the Raman spectrum six phonon bands are expected, as the biphenyl crystal at room temperature has two intercliange equivalent molecules (site symmetry $\mathrm{C}_{\mathrm{i}}$ ) per primitive cell [4] . At $55^{\circ} \mathrm{K}$ (fig. 1 ) we see five phonon bands of external vibrations (determined from the amalgamation limit criterion $[5,6]$, at frequencies of $41,67,71,107$ and $117 \mathrm{~cm}^{-1}$. The sixth band is suspected to be at around $30 \mathrm{~cm}^{-1}$. At $15^{\circ} \mathrm{K}$ the high temperature features remain essentially unaltered, while at least $\overline{\bar{T}}^{\dot{\bar{t}}}$ three additional weak bands ap-

* Supported by NSE Grant GH-32578X1 and NIH Grant NS08116.

$\dagger$ Other less prominent peaks are also appearing at low temperatures, see re[. [7]. pear reproducibly at 49,58 and $78 \mathrm{~cm}^{-1}$. These weak bands being in the amalgamation limit $[5,6]$ must also be plonos (or torsions). The possibility that they are phonon overtones and/or combination bands is ruled out on the following grounds: (i) overtones or combina. tion bands being due 10 a multi-phonon process are expected to grow in intensity as the temperature is increased, but we observe the reverse; (ii) the $49 \mathrm{~cm}^{-1}$ peak is too low in energy to be accounted for as either an overtone or combination band of the observed plionon bands; (iii) in this molecular crystal, overtones and combinations are expected to have a two particle exc:tation character [8] and should thus be broad compared to one-phonon peaks. This also is not observed.

In the intramolecular region the major Raman bands are again very similar at both high and low temperature (fig. 1). Even the doublet at $740 \mathrm{~cm}^{-1}$, which we have established to be due to Davydov splitting (from our isotopic mixed crystal criterion [9]), remains nearly the same at both temperatures. Yet at low temperature $\left(15-40^{\circ} \mathrm{K}\right.$ ) at least five additional peaks (not due to overtones and/or combination bands) appear in the Raman spectrum. this time at $136,188,389,825$ and $961 \mathrm{~cm}^{-1}$. A careful temperature dependence study shows an extremely wide transition region, with new bands appearing gradually. One example is shown in fig. 2, where we see that the strongest new feature is 


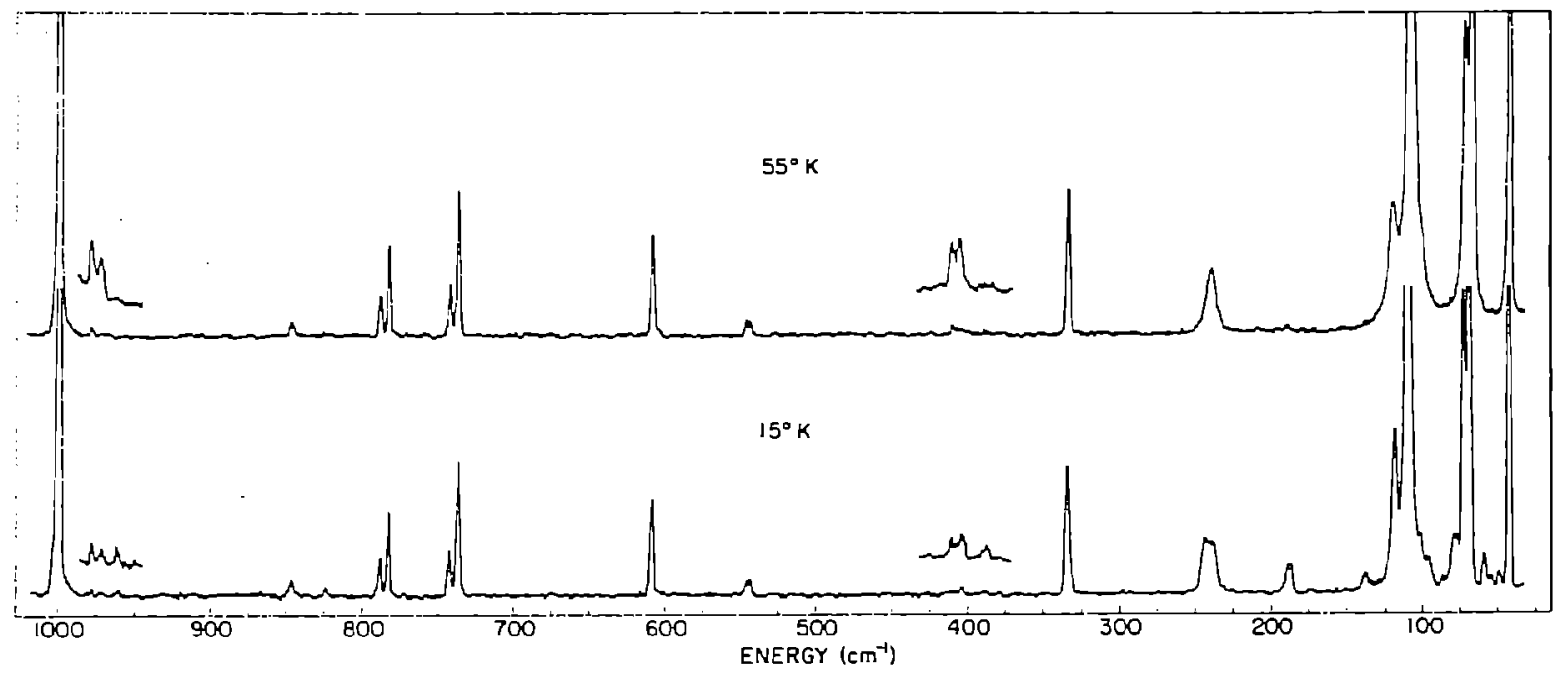

Fig. 1. Raman spectra of biphenyl- $h_{10}$ at $55^{\circ} \mathrm{K}$ (top) and $15^{\circ} \mathrm{K}$ (bottom) recorded photoelectrically on a Spex Ramalog $\mathrm{40}$ l double monochromitor (resolution $\approx 1 \mathrm{~cm}^{-1}$ ), using thı $4880 \mathrm{~A}$ line of an argon ion laser as the excilation source.

discernible already at $65^{\circ} \mathrm{K}$. We stress that all our data are completely reproducible and reversible with temperature cycling.

In summary. we observe that as the crystal is cooled, the high temperature Raman bands continue to retain their identity, however, in the low temperature range $\left(15-40^{\circ} \mathrm{K}\right)$, additional new bandis graclually energe both in the phonen and intramolecular regions (biphenyl $d_{\mathbf{i} 0}$ crystal sloows an andiogous beliaviour [7] to biphenyl- $h_{10}$ ). This suggests that at low temperature some sort of structural change of very inild character is taking place, for if a large change in the crystal structure were occurring. it would be expected to significantly alter both the appearance of the phonon spectrum [10] and of the Davydov splitting.

Of the eight low temperature $\left(15^{\circ} \mathrm{K}\right)$ Raman bands so far described, the three appearing at 78, 136 and $188 \mathrm{~cm}^{-1}$ correlate closely with the far-infrared peaks [7] seen by us (pieliminary data) at 76.133 and 188 $\mathrm{cm}^{-1}\left(47^{\circ} \mathrm{K}\right)$. These infrared frequencies are in general agreement with previous work [11.12]. Also, the (new) Raman bands appearing at about 389,825 and 961 $\left(15^{\circ} \mathrm{K}\right)$ correlate with $A_{u}$ infrared bands $[2,11,13]$, located around 401,839 and $968 \mathrm{~cm}^{-1}\left(93^{\circ} \mathrm{K}\right)$ [11] . This correspondence between Raman and infrared bands indicates that biphenyl has lost its center of inversion $\stackrel{\bar{t}}{\frac{1}{.}}$.
Of the three most feasible non-centrosymmetric static molecular deformations (long axis twist, out-of-plane ring-ring bending, in-plane ring-ring bending) we expect the one caused by a long axis twist $\left(D_{2}\right)$ to be the most likely one taking place, because the long axis twist involves the softest force field. Also, if either of the two ring-ring bending molecular deformations $\left(C_{2 v}\right)$ were occurring, a large frequency shift would be expected in the corresponding bending vibrations ( 133 and 188 $\mathrm{cm}^{-1}$ at $47^{\circ} \mathrm{K}$ ). No such effect lias been observed.

Our temperature dependence study shows that the structural change occurs grachaully (also reversibly and reproducibly) as $k T$ varies by a factor of three or more ${ }^{\star}$. We stress here that the observed continuous change involves at least three external and five internal modes (as opposed to just a single degree of freedom). This seems to us to be unprecedented.

The $2{ }^{\circ} \mathrm{K}$ fluorescence spectrum of the isotopic mixed

\# Lecolier et al. [12] have recently reported the far-infrared spectrum of the biphenyl crystal at several temperatures. A peak appears in their $15^{\circ} \mathrm{K}$ spectrum at $67 \mathrm{~cm}^{-1}$, which is not seen at $80^{\circ} \mathrm{K}$. We attribute this low temperature peak to a Raman allowed phonon, being made infrared active through a loss of the molecular center of inversion.

- Heat capacity measurements are underway. We observe at $1.5^{\circ} \mathrm{K}$ essentially the same Raman spectrum as at $15^{\circ} \mathrm{K}$. 


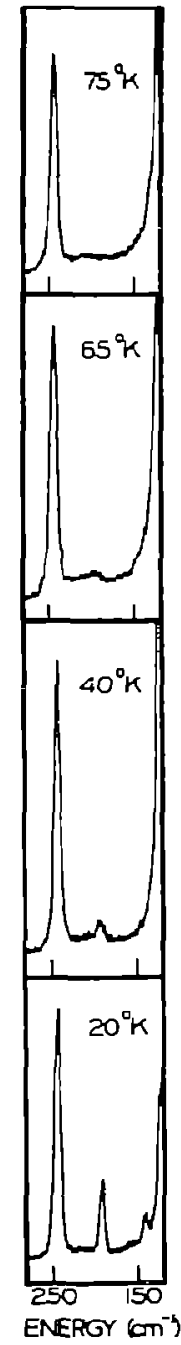

Fig. 2. Temperarure dependence study of the Raman spectrum of biphenyl- $h_{10}$ crystal in the region $100-300 \mathrm{~cm}^{-1}$. crystal ( $1 \not r_{0}$ biphenyl $/ h_{10}$ in biphenyl- $d_{10}$ ) shows a splitting of approximately $11 \mathrm{~cm}^{-1}$ on virtually every major vibronic band $[7,14]$ and cannot be explained by the room temperature crystal structure. Such a splitting would be consistent with our proposed non-centrosymmetric biphenyl structure, in that a pair of such deformed biphenyl molecules can have two possible mutual orientations of slightly different energy.

\section{References}

[1] O. Bastiansen, Acta Cliem. Scand. 3 (1949) 408; A. Almenningen and $O$. Bastiansen, $K g$. Norske Videnskab. Selskabs Skrifter No. 4. (1958).

[2] R.M. Barrett and D. Steele, J. Mol. Struct. 11 (1972) 105.

[3] II. Suzuki. Bull. Chem. Soc. Japan 32 (1959) 1340; A. Bree, C.Y. Pang and L. Rabeneck, Spectrcchim. Acta 27a (1971) 1293;

E.D. Schmid and B. Brosi, J. Chem. Phys. 56 (1972) 6267.

[4] G. Robertson, Nature I9 (1961) 593;

J. Trolter, Actu Cryst. 14 (1965) 1135

A. Hargreaves and S.H. Rizvi, Acta Cryst. 15 (1962) 365.

[5] P.N. Prasad and R. Kopelman, J. Chem. Pliys. 57 (1972) 863.

[6] P.N. Prasad and R. Kopelman, Chem. Plys. Letters 21 (1973) 505 .

[7] P.S. Friedman. R. Kopclman and P.N. Prasad, unpublished; Moleculir Structure and Spectroscopy Symposium, Ohio State University, Columbus, Y4 (1973).

[8] D.A. Dows and V. Schettino, J. Chem. Phys. 58 (1973) 5009.

[9] P.N. Prisad and R. Kopelman, J. Chem. Phys. 57 (1972) 856.

[10] P.N. Prasad and R. Kopelman, Clicm. Phys. Letters 20 (1973) 513.

[11] B. Pasquier, Mol. Cryst. Liquid Cryst. 11 (1970) 35.

[12] G.V. Lecolier, B. Wyncke and A. Hadni. J. Chem. Phys. 68 (1971) 1606.

[13] G. Zerbi and S. Sundroni, Spectrocliim. Acta 24A (1968) 483,511 ; privite communication.

[14] R.M. Hochstrasser, R.D. MCAlpine and J.D. Whitenın, J. Chem. Plyys. 58 (1973) 5078 